\title{
Is inequity undermining Australia's 'universal' health care system? Socio-economic inequalities in the use of specialist medical and non-medical ambulatory health care
}

\begin{abstract}
Objectives: To quantify need-adjusted socioeconomic inequalities in medical and nonmedical ambulatory health care in Australia and to examine the effects of specific interventions, namely concession cards and private health insurance $(\mathrm{PHI})$, on equity. Methods: We used data from a 2004 survey of 10,905 Australian women aged 53 to 58 years. We modelled the association between socio-economic status and health service use - GPs, specialists, hospital doctors, allied and alternative health practitioners, and dentists - adjusting for health status and other confounding variables. We quantified inequalities using the relative index of inequality (RII) using Poisson regression. The contribution of concession cards and $\mathrm{PHI}$ in promoting equity/inequity was examined using mediating models.
\end{abstract}

Results: There was equality in the use of GP services, but socio-economically advantaged women were more likely than disadvantaged women to use specialist (RII $=1.41,95 \% \mathrm{Cl}: 1.26-1.58)$, allied health (RII=1.21,1.12-1.30), alternative health (RII=1.29,1.13-1.47) and dental services (RII=1.61,1.48-1.75) after adjusting for need, and they were less likely to visit hospital doctors (RII=0.74,0.57-0.96). Concession cards reduced socio-economic inequality in GP but not specialist care. Inequality in dental and allied health services was partly explained by inequalities in $\mathrm{PHI}$.

Conclusions and implications: Substantial socio-economic inequity exists in use of specialist and non-medical ambulatory care in Australia. This is likely to exacerbate existing health inequalities, but is potentially amenable to change. Key words: health care inequalities, socioeconomic status, ambulatory care.

Aust N Z J Public Health. 2009; 33:458-65 doi: 10.1111/j.1753-6405.2009.00430.x

\author{
Rosemary J. Korda \\ Australian Centre for Economic Research on Health, The Australian National \\ University, Australian Capital Territory
}

Emily Banks, Mark S. Clements

National Centre for Epidemiology and Population Health, The Australian National University, Australian Capital Territory

\section{Anne F. Young}

Research Centre for Gender, Health \& Ageing, University of Newcastle, New South Wales
$\mathrm{H}$ orizontal equity - equal care for equal need - is an underlying objective of health care systems in most OECD countries, including Australia. ${ }^{1}$ Ambulatory health care - that is, health care provided to patients who are not admitted to hospital - is largely provided in private clinics on a fee-for-service basis; however, Medicare subsidises the cost of most doctor visits and there are provisions to limit outof-pocket costs. These include: incentives for doctors to bulk-bill resulting in no outof-pocket cost to the patient, a provision particularly aimed at low income households who hold concession cards; and a 'Safety Net' whereby all out-of-pocket medical costs over a certain annual threshold are subsidised.

Nevertheless, equity in ambulatory health care is far from guaranteed. Ambulatory care encompasses a large range of non-medical health services, including allied health, alternative health and dental services, most of which are not subsidised at all. Even for medical services that are subsidised, out-ofpocket costs can be substantial, and while private health insurance allows better access to non-medical services, not all can afford to hold it. For a given level of need, then, socioeconomically disadvantaged individuals may be less likely to use ambulatory health care services, particularly services beyond the GP. Yet there is a considerable evidence that socio-economically disadvantaged people are more likely than those who are better off to have chronic diseases and other health problems, ${ }^{2-4}$ and thus are the most likely to require such multidisciplinary care. And any inequalities in use of such health care are likely to only exacerbate health inequalities. Indeed, there is some evidence that in Australia, socio-economically advantaged individuals have obtained a disproportionate benefit of health care, contributing to widening relative health inequalities over time. $^{5}$

There has been considerable commentary concerning sources of inequity in Australia's health care system, ${ }^{6,7}$ however, there has been relatively little quantification of socio-economic inequalities in the use of ambulatory care services, based on need for service. It is known that socio-economically disadvantaged people are actually more
Submitted: October $2008 \quad$ Revision requested: March $2009 \quad$ Accepted: May 2009 Correspondence to:

Rosemary J. Korda, Australian Centre for Economic Research on Health, The Australian National University, Canberra, ACT 0200. Fax: (02) 61259123; e-mail: Rosemary.Korda @ anu.edu.au 
likely to visit a doctor than more advantaged individuals, ${ }^{3,8}$ which is not surprising given that lower socio-economic status (SES) is associated with higher morbidity. What is less clear is the extent to which use matches need for health care. No previous Australian study has examined inequalities across a full range of both medical and non-medical ambulatory services after adjusting for 'need' (effectively health status).

This study quantifies inequalities in both medical and nonmedical ambulatory care in a nationally representative sample of mid-age Australian women. Inequalities are examined across different chronic conditions and using various SES measures, and the contribution of concession cards and PHI in promoting equity/inequity is investigated.

\section{Methods}

We used data collected in 2004 from the mid-age cohort of women in the Australian Longitudinal Study of Women's Health (aged 53 to 58 years). The participants were initially selected in 1996 from the Medicare database, with random sampling within the age group except there was over-sampling in rural and remote areas. The initial response rate was estimated to be $53-56 \%,{ }^{9}$ and the response rate in 2004 was $85 \% .{ }^{10}$ Compared with the reference population, women who participated were more likely to be married, of English-speaking background, have either post-school qualifications or no formal qualifications and were less likely to be Indigenous. ${ }^{10}$ Further details on the recruitment methods and response rates can be found elsewhere. ${ }^{9,10}$

Women completed a 24-page closed-item postal questionnaire. Regarding health care, women were asked how many times they had consulted a GP, specialist and hospital doctor (outpatients or casualty) in the past 12 months (with six response options, ranging from 'none' to ' 25 or more times'), and whether or not they had consulted a dentist, allied health practitioner (physiotherapist, optometrist, dietician, counsellor/ psychologist/social worker, podiatrist) or alternative health practitioner (naturopath/herbalist, acupuncturist, chiropractor, osteopath, massage therapist, other alternative health practitioner). Responses were dichotomised as any use/no use in the past 12 months. For medical practitioner services, the frequency of use for those who had used the service at least once was also examined, with responses dichotomised as not frequent or frequent ( $>7$ visits for GPs and $>3$ visits for specialists and hospital doctors).

Socio-economic status was measured using household occupation, the only SES information collected in the 2004 survey (apart from area of residence which can be coded for SES). Occupation is considered to be perhaps the best single indicator of SES, as it incorporates elements of education, income and job status, ${ }^{11}$ and household occupation is a particularly sensitive measure of SES in women. ${ }^{12}$ Women indicated their own and their partner's occupation from a list of nine major occupational groups based on the Australian Standard Classification of Occupations, which were then classified into one of five skill levels (skill level 1 is highest SES). ${ }^{13}$ Each woman was assigned the skill level of the highest ranked occupation (self or partner). Women who had data missing on occupation - either because neither they nor their partners were in paid employment $(12 \%)$ or because there was insufficient information to code household occupation $(11 \%)$ - were excluded from the main analysis. Women with missing occupational data were more likely to reside in low SES areas $\left(\chi^{2}=35.9, p<0.001\right)$ than those without missing data.

Need for health care was proxied using three health variables - self-rated health ('excellent', 'very good', 'good', 'fair' or 'poor'), chronic illness and symptoms. Chronic illness was the number of chronic conditions out a possible 21 a women reported being diagnosed or treated for in the past three years. Symptoms was the proportion of symptoms experienced 'sometimes' or 'often' out of a possible 21 symptoms.

Three factors were included in the analyses as potential confounders in the relationship between SES and need-adjusted health-care use - region of residence (classified as 'major cities', 'inner regional', 'outer regional' or 'remote/very remote', based on Accessibility/Remoteness Index of Australia Plus scores ${ }^{14}$ ), marital status ('married/de facto' or 'single') and non-English speaking background (NESB) (born in an non-English-speaking country or not). We also entered age as a continuous variable in the models, but as this adjustment had no effect on inequality estimates it was excluded from the final models.

Poisson regression with robust variance estimation ${ }^{15}$ was used to model the associations between SES and health-care outcomes, adjusting for health status (except in the case of dental services) and potential confounding variables, incorporating the survey design in the analysis. Inequality was quantified using the relative index of inequality (RII). ${ }^{16,17}$ The RII is a relative risk constructed by estimating a regression coefficient for the mid-point of the cumulative proportion of the population in each of the five SES groups ordered from lowest to highest. It can be interpreted as the ratio of the probability of health service use at the most advantaged end of the SES continuum to the probability at the least advantaged end. STATA 9.0 statistical software was used for all analyses.

We also quantified the extent to which concession cards explain any SES variation in medical care and PHI explains any SES variation in non-medical care. To do this, the change in the RII when the mediating variable (concession card or ancillary PHI) was added to the model was estimated using the SUEST procedure in STATA. ${ }^{18}$

Because of the potential limitations on relying on household occupation (with $23 \%$ missing data) as the measure of SES, we also performed sensitivity analyses. First, we re-calculated inequality estimates using education level (highest qualification completed), which was collected in an earlier survey in 1996, to measure SES ( $0.8 \%$ missing data). RIIs using education were calculated twice - once excluding the $23 \%$ of women with missing occupational data and once on the 'full' sample (i.e. only $0.8 \%$ omitted due to missing education data). The RIIs across the two samples were then compared to examine the effect of excluding women with missing occupational data on inequality estimates. Second, using data collected on the same women in 2001, we 
compared inequalities in health service use across a range of SES variables that were collected in that survey - household occupation, household income (eight income categories, 27.8\% missing data) and an area-based SES measure (SEIFA Index of Relative Socio-Economic Disadvantage, 0.5\% missing data), as well as education (data collected in 1996).

The project was approved by The Australian National University Human Research Ethics Committee.

\section{Results}

Of the 8,353 women who supplied occupational data, nearly half were classified in the highest SES group (skill level 1), with

\section{Figure 1: Relative index of inequality (with $95 \%$ confidence intervals) for each health service}

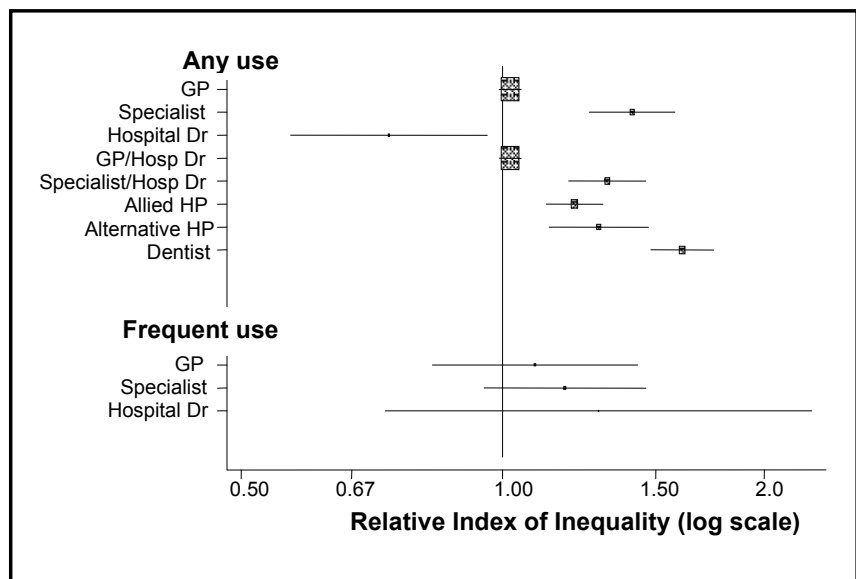

\section{Notes:}

1. GP/Hosp $D r=G P$ and/or a hospital doctor; Specialist/Hosp $D r=$ specialist and/or a hospital doctor; $H P=$ health practitioner.

2. Any use is at least one visit in the past 12 months; frequent use is frequent visits, conditional on any use.

3. Relative index of inequality is based on household occupation and is adjusted for region, marital status, and non-English-speaking background; and for all services except dental, is also adjusted for health status (selfrated health, symptoms and chronic illnesses). about $15 \%$ in each of levels 2 through 4 and $9 \%$ in the lowest group (skill level 5) (see Table 1).

Health service use for the total sample and by SES is described in Table 1. Almost all women (93\%) visited a GP in the past 12 months, $12 \%$ frequently; just under half (47\%) visited a specialist, $16 \%$ frequently; and $13 \%$ visited a hospital doctor, $3 \%$ frequently. Two-thirds of women used allied health (65\%) and/or dental (66\%) services, while $39 \%$ consulted an alternative health practitioner.

Modelled inequality estimates for health practitioner visits, adjusted for health status and other confounding variables, are summarised in the forest plot in Figure 1. Full model results are shown in Table 2 (any use) and Table 3 (frequent use). These show no significant inequality in the use of GP services. In contrast, the most advantaged women were $41 \%$ more likely to visit a specialist than the least advantaged, but they were less likely to visit a hospital-based doctor (Table 2). Analysing GP/hospital-based doctor services combined and specialist/hospital-based doctor services combined (these variables representing a possible upper limit of use of GP and specialist services, respectively), there remained no inequality in any use of GP services (RII $=1.02 ; 95 \%$ CI: 0.99-1.05) while specialist use continued to be pro-high-SES (RII=1.32; 95\% CI: 1.19-1.46). There was no significant inequality in terms of frequent visits, although estimates were imprecise due to the relatively low number of frequent users (Table 3).

There was significant inequality in use of non-medical services (Table 2 ). The most advantaged women were $21 \%$ more likely to use allied health services, $29 \%$ more likely to consult an alternative health practitioner, and $61 \%$ more likely to visit a dentist than the least advantaged women. Separate analysis for each of the allied health practitioner services (not shown in Table 2) showed significant pro-high SES inequalities for physiotherapist (RII=1.74; 95\% CI: 1.40-2.16), optometrist (RII=1.18; 95\% CI: 1.06-1.32), counsellor/psychologist/social worker (RII=1.98; $95 \%$ CI: $1.31-2.98)$, and podiatrist (RII $=1.41 ; 95 \% \mathrm{CI}: 1.07-1.86)$, but not for dietician (RII=0.95; 95\% CI: 0.59-1.54). Analysis

Table 1: Health service use (\%) by total study sample and socio-economic (SES), weighted for area.

\begin{tabular}{|c|c|c|c|c|c|c|c|c|}
\hline & \multirow{3}{*}{\multicolumn{2}{|c|}{ Total }} & \multirow{2}{*}{\multicolumn{5}{|c|}{$\begin{array}{c}\text { SES } \\
\text { Household Occupation Skill Level }\end{array}$}} & \multirow[t]{3}{*}{$p$-value } \\
\hline & & & & & & & & \\
\hline & & & 1 (High) & 2 & 3 & 4 & 5 (Low) & \\
\hline & $\mathrm{n}$ & 8,353 & 4,045 & 1,107 & 1,309 & 1,173 & 719 & \\
\hline & $\%$ & 100 & 48 & 13 & 16 & 14 & 9 & \\
\hline \multicolumn{9}{|l|}{ Medical practitioners } \\
\hline GP - any $(n=8,307)$ & & 92.8 & 92.7 & 91.8 & 93.8 & 92.7 & 93.4 & 0.600 \\
\hline GP - frequent $(n=8,307)$ & & 11.7 & 10.7 & 11.7 & 11.3 & 14.5 & 13.9 & 0.041 \\
\hline Specialist - any $(n=8,290)$ & & 47.1 & 50.0 & 46.2 & 44.3 & 42.8 & 43.4 & 0.001 \\
\hline Specialist - frequent $(n=8,290)$ & & 15.5 & 15.9 & 17.0 & 14.6 & 14.7 & 13.6 & 0.492 \\
\hline Hospital $\mathrm{Dr}-$ any $(n=8,121)$ & & 13.2 & 11.4 & 14.5 & 13.6 & 16.1 & 16.8 & 0.001 \\
\hline Hospital $\mathrm{Dr}-$ frequent $(\mathrm{n}=8,121)$ & & 2.5 & 2.3 & 2.4 & 3.0 & 2.3 & 4.1 & 0.203 \\
\hline \multicolumn{9}{|l|}{ Non-medical practitioners } \\
\hline Allied Health $(n=8,320)$ & & 65.3 & 67.4 & 64.0 & 65.8 & 61.7 & 59.5 & 0.003 \\
\hline Alternative Health Practitioner $(n=8,320)$ & & 38.9 & 40.0 & 41.7 & 37.2 & 37.1 & 33.3 & 0.021 \\
\hline Dentist $(n=8,320)$ & & 65.9 & 73.2 & 66.3 & 58.8 & 56.0 & 51.5 & $<0.001$ \\
\hline
\end{tabular}

\section{Notes:}

1. For medical practitioner services, 'any' is any visit in the past 12 months and 'frequent' is frequent visits, conditional on any use, where frequent is $>7$ visits for GPs and >3 visits for specialists and hospital doctors. For non-medical practitioners, use is any use in past 12 months.

2. $p$-value is for the association between household occupation level and health service use using chi-square test. 
of alternative health practitioner services showed no inequality in use of naturopath/herbalist (RII=1.21; 95\% CI: 0.95-1.63) or chiropractor (RII=1.14; 95\% CI: 0.89-1.46), while the most advantaged women were around twice as likely to consult an acupuncturist (adjusted RII $=2.21$; 95\% CI: 1.35-3.63), osteopath (adjusted RII $=2.22 ; 95 \%$ CI: $1.23-4.03$ ) or massage therapist (adjusted RII $=1.97 ; 95 \%$ CI: 1.61-2.41).

Patterns of inequalities within sub-samples of women reporting a particular chronic condition were also examined for all services excluding dental (see Figure 2). The pattern of inequalities is similar to that reported previously.

With regard to concession cards, $11 \%$ of women held a concession card, and this varied inversely with SES (7\% in the highest SES group and 34\% in lowest). After adjusting for concession card in the analysis of GP and specialist services, there was an increase of $6.3 \%$ (95\% CI: $0.0-12.8 \%)$ in the RII for frequent GP use (but no significant change for any use) suggesting that concession cards do attenuate inequality in these services. In contrast, concession cards had no significant effect on inequality in specialist services.

With regard to PHI, $65 \%$ of women held ancillary insurance, with the most advantaged more likely to have cover than the least ( $72 \%$ versus $42 \%$ ). After entering ancillary insurance in the models, there was a significant decrease in the RII for both dental [7.9\% (95\% CI: $6.1-9.7 \%)$ decrease] and allied health services [7.3\% (95\% CI: 5.6-9.0\%) decrease], consistent with the notion that pro-high-SES inequality in use of these services is partly mediated through PHI.

The sensitivity analysis that examined the effect on inequality estimates of excluding women with missing occupational data showed that inequality was underestimated for frequent GP visits and alternative health practitioner visits. The analysis that

Table 2: Risk ratios for any use of heath service in relation to SES and other explanatory factors.

\begin{tabular}{|c|c|c|c|c|c|c|c|c|c|}
\hline & \multicolumn{3}{|c|}{ General Practitioner } & \multicolumn{3}{|c|}{ Specialist } & \multicolumn{3}{|c|}{ Hospital Doctor } \\
\hline & $\mathbf{R R}$ & $95 \% \mathrm{Cl}$ & $p$ & $\mathbf{R R}$ & $95 \% \mathrm{Cl}$ & $p$ & $\mathbf{R R}$ & $95 \% \mathrm{Cl}$ & $p$ \\
\hline SES & 1.02 & $0.99-1.05$ & 0.199 & 1.41 & $1.26-1.58$ & $<0.001$ & 0.74 & $0.57-0.96$ & 0.022 \\
\hline \multicolumn{10}{|l|}{ Region } \\
\hline - Major cities & 1.00 & - & - & 1.00 & - & - & 1.00 & - & - \\
\hline - Inner Regional & 0.98 & $0.97-1.00$ & 0.053 & 0.88 & $0.83-0.94$ & $<0.001$ & 1.25 & $1.07-1.45$ & 0.004 \\
\hline - Outer Regional & 0.99 & $0.97-1.01$ & 0.273 & 0.81 & $0.75-0.89$ & $<0.001$ & 1.22 & $1.02-1.46$ & 0.028 \\
\hline - Remote & 0.98 & $0.95-1.02$ & 0.375 & 0.80 & $0.68-0.93$ & 0.005 & 1.43 & $1.09-1.86$ & 0.009 \\
\hline Marital Status (Single) & 0.99 & $0.97-1.01$ & 0.281 & 0.94 & 086-1.01 & 0.101 & 1.12 & $0.94-1.34$ & 0.215 \\
\hline NESB (Non-English) & 0.97 & $0.94-1.00$ & 0.062 & 0.99 & $0.89-1.09$ & 0.819 & 1.21 & $0.97-1.53$ & 0.097 \\
\hline \multicolumn{10}{|l|}{ Self-Rated Health } \\
\hline - Excellent & 1.00 & - & - & 1.00 & - & - & 1.00 & - & - \\
\hline - Very good & 1.07 & $1.03-1.11$ & $<0.001$ & 1.15 & $1.02-1.30$ & 0.027 & 1.39 & $1.01-1.92$ & 0.046 \\
\hline - Good & 1.09 & $1.05-1.13$ & $<0.001$ & 1.32 & $1.17-1.49$ & $<0.001$ & 1.87 & $1.35-2.58$ & 0.001 \\
\hline - Fair & 1.11 & $1.07-1.15$ & $<0.001$ & 1.61 & $1.40-1.84$ & $<0.001$ & 3.00 & $2.11-4.27$ & $<0.001$ \\
\hline - Poor & 1.06 & $0.98-1.14$ & 0.161 & 1.68 & $1.36-2.07$ & $<0.001$ & 3.91 & $2.41-6.35$ & $<0.001$ \\
\hline Symptoms & 1.05 & $1.01-1.10$ & 0.016 & 1.33 & $1.13-1.58$ & 0.001 & 2.04 & $1.36-3.06$ & 0.001 \\
\hline \multirow[t]{3}{*}{ Chronic Illness } & 1.03 & $1.02-1.03$ & $<0.001$ & 1.14 & $1.11-1.16$ & $<0.001$ & 1.13 & 1.07-1.19 & $<0.001$ \\
\hline & \multicolumn{3}{|c|}{ Allied Health Practitioner } & \multicolumn{3}{|c|}{ Alternative Health Practitioner } & \multicolumn{3}{|c|}{ Dentist } \\
\hline & RR & $95 \% \mathrm{Cl}$ & $p$ & $\mathbf{R R}$ & $95 \% \mathrm{Cl}$ & $p$ & $\mathbf{R R}$ & $95 \% \mathrm{Cl}$ & $p$ \\
\hline SES & 1.21 & $1.12-1.30$ & $<0.001$ & 1.29 & 1.13-1.47 & $<.001$ & 1.61 & $1.48-1.75$ & $<0.001$ \\
\hline \multicolumn{10}{|l|}{ Region } \\
\hline - Major cities & 1.00 & - & - & 1.00 & - & - & 1.00 & - & - \\
\hline - Inner Regional & 0.95 & $0.91-0.99$ & 0.014 & 1.09 & $1.01-1.17$ & 0.023 & 0.90 & $0.86-0.94$ & $<0.001$ \\
\hline - Outer Regional & 0.89 & $0.84-0.94$ & $<0.001$ & 1.12 & $1.02-1.22$ & 0.016 & 0.81 & $0.76-0.86$ & $<0.001$ \\
\hline - Remote & 0.95 & $0.91-1.08$ & 0.844 & 1.08 & $0.91-1.27$ & 0.399 & 0.81 & $0.71-0.91$ & $<0.001$ \\
\hline Marital Status (Single) & 0.97 & $0.92-1.03$ & 0.317 & 1.16 & $1.07-1.27$ & 0.001 & 1.04 & 0.98-1.09 & 0.170 \\
\hline NESB (Non-English) & 0.97 & $0.90-1.04$ & 0.356 & 1.01 & $0.89-1.14$ & 0.878 & 1.02 & 0.95-1.09 & 0.618 \\
\hline \multicolumn{10}{|l|}{ Self-Rated Health } \\
\hline -Excellent & 1.00 & - & - & 1.00 & - & - & - & - & - \\
\hline - Very good & 1.07 & 099-1.15 & 0.094 & 1.09 & $0.96-1.24$ & 0.183 & - & - & - \\
\hline - Good & 1.07 & $0.99-1.15$ & 0.123 & 1.09 & $0.96-1.24$ & 0.199 & - & - & - \\
\hline - Fair & 1.12 & $1.02-1.22$ & 0.016 & 1.09 & $0.93-1.28$ & 0.293 & - & - & - \\
\hline - Poor & 1.14 & $0.98-1.34$ & 0.096 & 1.17 & $0.83-1.66$ & 0.363 & - & - & - \\
\hline Symptoms & 1.36 & $1.21-1.53$ & $<0.001$ & 1.93 & $1.57-2.36$ & $<0.001$ & - & - & - \\
\hline Chronic Illness & 1.06 & $1.04-1.08$ & $<0.001$ & 1.04 & $1.01-1.07$ & 0.007 & - & - & - \\
\hline
\end{tabular}

Notes:

1. $R R=$ risk ratio; $\mathrm{Cl}=$ confidence interval; $S E S$ = socioeconomic status (household occupation).

2. The RR for SES is the relative index of inequality (RII).

3. Risk ratios are adjusted for each factor in the model. 
Table 3: Risk ratios for frequent visits to medical practitioners in relation to SES and other explanatory factors.

\begin{tabular}{|c|c|c|c|c|c|c|c|c|c|}
\hline & \multicolumn{3}{|c|}{ General Practitioner } & \multicolumn{3}{|c|}{ Specialist } & \multicolumn{3}{|c|}{ Hospital Doctor } \\
\hline & $\mathbf{R R}$ & $95 \% \mathrm{Cl}$ & $p$ & $\mathbf{R R}$ & $95 \% \mathrm{Cl}$ & $p$ & RR & $95 \% \mathrm{Cl}$ & $p$ \\
\hline SES & 1.09 & $0.83-1.43$ & 0.547 & 1.18 & $0.95-1.46$ & 0.136 & 1.29 & $0.73-2.26$ & 0.379 \\
\hline \multicolumn{10}{|l|}{ Region } \\
\hline - Major cities & 1.00 & - & - & 1.00 & - & - & 1.00 & - & - \\
\hline - Inner Regional & 0.74 & $0.63-0.86$ & $<0.001$ & 0.79 & $0.70-0.89$ & $<0.001$ & 0.80 & $0.56-1.13$ & 0.200 \\
\hline - Outer Regional & 0.72 & $0.59-0.87$ & 0.001 & 0.69 & $0.58-0.83$ & $<0.001$ & 1.04 & $0.69-1.56$ & 0.863 \\
\hline - Remote & 1.12 & $0.81-1.54$ & 0.488 & 0.67 & $0.45-1.01$ & 0.056 & 1.32 & $0.84-2.05$ & 0.227 \\
\hline Marital Status (Single) & 1.04 & $0.86-1.26$ & 0.653 & 1.09 & $0.95-1.26$ & 0.233 & 1.44 & $1.02-2.03$ & 0.039 \\
\hline NESB (Non-English) & 1.10 & $0.86-1.41$ & 0.448 & 0.95 & $0.78-1.16$ & 0.627 & 1.34 & $0.85-2.09$ & 0.203 \\
\hline \multicolumn{10}{|l|}{ Self-Rated Health } \\
\hline - Excellent & 1.00 & - & - & 1.00 & - & - & 1.00 & - & - \\
\hline - Very good & 4.58 & $2.10-9.98$ & $<0.001$ & 1.77 & $1.22-2.57$ & 0.003 & 2.88 & $0.57-14.40$ & 0.198 \\
\hline - Good & 8.74 & $4.10-19.11$ & $<0.001$ & 2.27 & $1.58-3.28$ & $<0.001$ & 4.12 & $0.82-20.78$ & 0.087 \\
\hline - Fair & 15.03 & $6.90-32.75$ & $<0.001$ & 3.57 & $2.46-5.19$ & $<0.001$ & 5.77 & $1.10-30.23$ & 0.038 \\
\hline - Poor & 18.43 & $7.76-43.78$ & $<0.001$ & 4.21 & $2.76-6.42$ & $<0.001$ & 9.41 & $1.57-56.48$ & 0.014 \\
\hline Symptoms & 1.88 & $1.25-2.81$ & 0.002 & 1.03 & $0.76-1.41$ & 0.836 & 1.96 & $0.86-4.48$ & 0.109 \\
\hline Chronic Illness & 1.29 & $1.23-1.37$ & $<0.001$ & 1.14 & $1.10-1.19$ & $<0.001$ & 1.06 & $0.95-1.19$ & 0.273 \\
\hline
\end{tabular}

Notes: $1 . R R$ = risk ratio; $\mathrm{Cl}$ = confidence interval; $S E S$ = socioeconomic status (household occupation). 2 . The $R R$ for SES is the relative index of inequality (RII). 3. Risk ratios are adjusted for each factor in the model.

Figure 2: Relative index of inequality (with $95 \%$ confidence intervals) for any use of each health service by chronic condition.

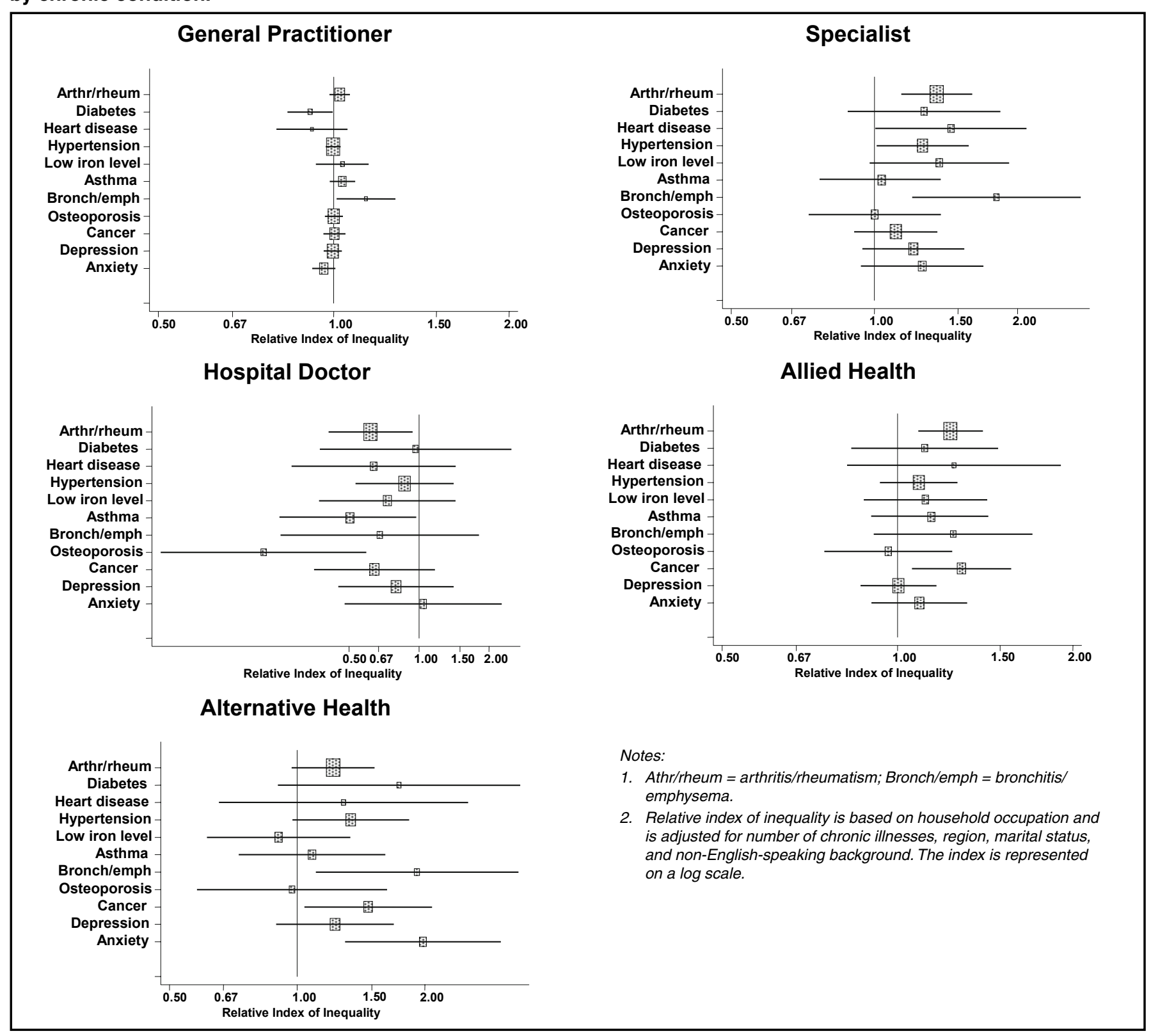


compared inequalities across SES measures using data collected in the 2001 survey show the pattern of health care inequalities to be similar across all SES variables (see Table 4). Associations tended to be strongest for household occupational status and weakest for area SES.

\section{Discussion}

There is inequity in the use of ambulatory health care in Australia. For a given level of need, socio-economically advantaged women are more likely to use specialist medical, allied health, alternative health and dental services than less advantaged women; at the same time, they are equally likely to visit a GP and are less likely to use hospital-based medical services. Concession cards reduce inequality in GP use but have no effect on specialist care, while PHI explains some of the inequality in use of nonmedical services.

The debate about equal access to ambulatory health care services in Australia has largely been focused on GP services. This study examined inequity in a range of services, including specialist medical, allied health, alternative health and dental services; these have not been studied systematically before. The findings show that the problem of inequity lies beyond the GP. This is important, particularly in the context of chronic disease where optimal care includes use of multidisciplinary services.

A primary limitation of the study is that the health service data are self-reported. There is a tendency to under-report health service use ${ }^{19}$ however, the extent to which this may or may not bias the inequality findings is uncertain as it depends on whether there is differential reporting bias by SES, which is unknown. A further limitation is that need for services cannot be truly measured and health status is a crude measure of need. Another limitation is that because of initial non-response rates and missing data on household occupation, which was more common in lower SES women, the inequality estimates may be biased. In particular, given there was an under-representation of lower SES women in the initial study sample, and that the RII is based on the proportion of women in each SES group, the effect of this is, ceteris paribus, an underestimation of pro-high-SES inequality in health service use. The sensitivity analysis confirmed that missing occupational data was, if anything, likely to result in an underestimate of inequality.

Table 4: Relative index of inequality (RII) for health service use across different SES variables.

\begin{tabular}{|c|c|c|c|c|c|c|}
\hline & \multicolumn{3}{|c|}{ Any use } & \multicolumn{3}{|c|}{ Frequent use } \\
\hline & RII & $95 \% \mathrm{Cl}$ & $p$-value & RII & $95 \% \mathrm{Cl}$ & $p$-value \\
\hline \multicolumn{7}{|l|}{ General Practitioner } \\
\hline Household occupation & 1.01 & $0.99-1.04$ & 0.385 & 0.88 & $0.68-1.12$ & 0.290 \\
\hline Education & 1.00 & $0.98-1.03$ & 0.781 & 0.89 & $0.73-1.08$ & 0.221 \\
\hline Household Income & 1.03 & $1.00-1.06$ & 0.031 & 0.96 & $0.75-1.24$ & 0.773 \\
\hline Area SES - IRSD & 1.01 & $0.99-1.03$ & 0.433 & 0.82 & $0.67-0.98$ & 0.030 \\
\hline \multicolumn{7}{|l|}{ Specialist } \\
\hline Household occupation & 1.49 & $1.34-1.66$ & $<0.001$ & 1.09 & $0.88-1.35$ & 0.406 \\
\hline Education & 1.45 & $1.33-1.58$ & $<0.001$ & 1.19 & $1.00-1.41$ & 0.048 \\
\hline Household Income & 1.36 & $1.22-1.52$ & $<0.001$ & 1.09 & $0.88-1.36$ & 0.422 \\
\hline Area SES - IRSD & 1.23 & $1.12-1.35$ & $<0.001$ & 1.06 & $0.89-1.26$ & 0.535 \\
\hline \multicolumn{7}{|l|}{ Hospital Doctor } \\
\hline Household occupation & 0.87 & $0.68-1.10$ & 0.240 & 0.66 & $0.37-1.18$ & 0.159 \\
\hline Education & 0.97 & $0.79-1.18$ & 0.729 & 0.69 & $0.46-1.02$ & 0.063 \\
\hline Household Income & 0.93 & $0.72-1.20$ & 0.574 & 0.44 & $0.25-0.77$ & 0.004 \\
\hline Area SES - IRSD & 1.05 & $0.86-1.29$ & 0.625 & 0.83 & $0.55-1.24$ & 0.363 \\
\hline \multicolumn{7}{|l|}{ Allied health } \\
\hline Household occupation & 1.28 & $1.19-1.39$ & $<0.001$ & - & - & - \\
\hline Education & 1.30 & $1.21-1.39$ & $<0.001$ & - & - & - \\
\hline Household Income & 1.36 & $1.25-1.48$ & $<0.001$ & - & - & - \\
\hline Area SES - IRSD & 1.17 & $1.09-1.26$ & $<0.001$ & - & - & - \\
\hline \multicolumn{7}{|l|}{ Alternative health } \\
\hline Education & 1.30 & $1.12-1.50$ & $<0.001$ & - & - & - \\
\hline Household Income & 1.27 & $1.06-1.53$ & 0.009 & - & - & - \\
\hline Area SES - IRSD & 1.40 & $1.19-1.64$ & $<0.001$ & - & - & - \\
\hline \multicolumn{7}{|l|}{ Dentist } \\
\hline Household occupation & 1.70 & $1.57-1.83$ & $<0.001$ & - & - & - \\
\hline Education & 1.76 & $1.65-1.88$ & $<0.001$ & - & - & - \\
\hline Household Income & 1.71 & $1.58-1.85$ & $<0.001$ & - & - & - \\
\hline Area SES - IRSD & 1.38 & $1.28-1.48$ & $<0.001$ & - & - & - \\
\hline
\end{tabular}


Similar findings of inequity in specialist medical, but not necessarily GP, services has been reported previously in Australia ${ }^{20}$ and a number of other countries with universal public health insurance. ${ }^{21}$ Other Australian studies have also reported inequity in use of GP services in particular groups..$^{22,23}$ For allied health services there is no recent Australian-based research with which to directly compare this study's results. Inequalities in counselling services in the study accords with a previous report of inequality in use of psychologists. ${ }^{24}$ In contrast, the findings of inequalities in allied health services differ from previous smaller studies that showed no inequalities in use of optometrists ${ }^{25}$ or physiotherapists, chiropractors or massage therapists. ${ }^{26}$ The substantial socioeconomic inequality found in dental visits is consistent with previous research, ${ }^{27-29}$ and previous studies have shown inequality in use of alternative health practitioners, unadjusted for health status. ${ }^{30}$

The pattern of findings suggests that inequalities in care are to some extent shaped by the health care system itself, where outof-pocket costs and private care influence access. International findings are in line with these conclusions - inequity in ambulatory medical and dental care in universal systems is found to be greatest in countries where PHI and direct private payments play some role in the access to services. ${ }^{21}$ Nevertheless, explanations of health care inequalities are likely to go beyond simply an inability to pay for services. Inequalities are likely to reflect other dimensions of SES, particularly education, as more highly-educated individuals are better able to navigate the health system and advocate for services. Inequality could also reflect provider characteristics: there is evidence that some doctors view socio-economically disadvantaged patients more negatively than those who are not disadvantaged and consider them less likely to comply with treatment. $^{31,32}$ Given that Australia has a gate-keeping system, whereby GPs essentially control access to specialists services and may refer patients to allied health services, it is possible that some GPs are selective in whom they refer, for example, they may not refer someone who they know cannot afford to pay for the service.

While it is assumed that need-adjusted inequalities in health care are inequitable, inequality in use of services may not necessarily be unfair if it merely reflects differences in an individuals' preferences to use health care. Nonetheless, a low propensity for disadvantaged women to seek care was not evident in the use of GP services. In addition, the study largely assumes that the amount of care received by the more advantaged women is appropriate while disadvantaged women are not receiving the care they need. However, this study cannot rule out that there is over-servicing of advantaged women. Nevertheless, this in itself could still be considered inequitable in that health expenditure is not being distributed according to need.

In terms of health system implications, the findings lead to questions, some raised before, regarding whether or not the current equity-promoting features of the system should be extended. For example, although Medicare items for chronic disease management have been introduced for limited allied health services, should this program be extended to include more services and a greater range of patients? Should bulk-billing incentives offered to GPs be extended to specialist doctors? What other options could be created for minimising out-of-pocket payments? The findings also support experts who have questioned the existence of the government's PHI rebate (equal to 30 to $40 \%$ of the cost of the insurance), which effectively subsidises care for those who can afford insurance, while those who cannot afford it often miss out on this care altogether. ${ }^{7}$

Finally, given that for certain conditions access to care beyond the GP generally provides more comprehensive health care and potentially better health outcomes, these findings are likely to be important in partly explaining socio-economic inequalities in health. However, it is not known from this study to what extent the statistically significant differences in use represent clinically significant findings in terms of health outcomes. Regardless, it would be hard to argue that the findings are not important. They raise questions about distributive justice in a mixed public/private health care system that is universal but not comprehensive. They suggest unfairness and inefficiency in the allocation of services, as those who are sickest, and hence potentially have the greatest capacity to benefit from health care, are not those most likely to receive it.

\section{Acknowledgements}

The Australian Longitudinal Study on Women's Health, which was conceived and developed at the Universities of Newcastle and Queensland, is funded by the Australian Government Department of Health and Ageing. We thank all participants for their valuable contribution to this project. The authors would also like to acknowledge the research advice provided by Professor Jim Butler from the Australian Centre for Economic Research on Health at the Australian National University.

\section{References}

1. Organisation for Economic Co-operation and Development. Towards High Performing Health Systems [monograph on the Internet]. Paris (FRA): OECD; 2004 [cited 2008 Jun]. Available from: http://www.sourceoecd.org/

2. Draper G, Turrell G, Oldenburg B. Health Inequalities in Australia: Mortality. Brisbane (AUST): Queensland University of Technology; 2004. Health inequalities Monitoring Series NO. 1. AIHW Catalogue No.: PHE 55.

3. Turrell G, Stanley L, de Looper M, Oldenburg B. Health Inequalities in Australia: Morbidity, Health Behaviours, Risk Factors and Health Service Use. Brisbane (AUST): Queensland University of Technology; 2006. Health Inequalities Monitoring Series No. 2. AIHW Catalogue No.: PHE 72.

4. Glover J, Hetzel D, Tennant S. The socio-economic gradient and chronic illness and associated risk factors in Australia. Australia and New Zealand Health Policy. 2004;1(1):8.

5. Korda RJ, Butler JR, Clements MS, Kunitz SJ. Differential impacts of health care in Australia: trend analysis of socio-economic inequalities in avoidable mortality. Int J Epidemiol. 2007;36(1):157-65.

6. Mooney G. Access and service delivery issues in Productivity Commission and Melbourne Institute of Applied Economic and Social Research. Proceedings of the Health Policy Round Table; 2002 March 7-8; Melbourne, Australia. Canberra (AUST): Ausinfo; 2002. p. 161-93

7. Richardson JR. Priorities of health policy: cost shifting or population health. Aust New Zealand Health Policy. 2005;2(1):1.

8. Glover J, Harris K, Tennant S. A Social Health Atlas of Australia. 2nd ed. Adelaide (AUST): Public Health Information Development Unit, University of Adelaide; 1999. 
9. Lee C, Dobson AJ, Brown WJ, Bryson L, Byles J, Warner-Smith P, et al. Cohort profile: The Australian Longitudinal Study on Women's Health. Int J Epidemiol. 2005;34(5):987-91.

10. Powers J. Cohorts with women of the same age in the 2001 census. In: The Australian Longitudinal Study on Women's Health [technical report on the Internet]. Newcastle (AUST): Research Centre for Gender, Health \& Ageing, The University of Newcastle; 2004 [cited 2008 Jun]. Technical Report No.: 23 Dec 2004. Available from: http://www.alswh.org.au/Reports/Technical/ Report\%2023\%20ALSWH.pdf

11. Liberatos P, Link BG, Kelsey JL. The measurement of social class in epidemiology. Epidemiol Rev. 1988;10:87-121.

12. Krieger N, Chen JT, Selby JV. Comparing individual-based and householdbased measures of social class to assess class inequalities in women's health: a methodological study of 684 US women. J Epidemiol Community Health. 1999;53(10):612-23.

13. Australian Bureau of Statistics. Australian Standard Classification Of Occupations. 2nd ed. Canberra: ABS; 1997. ABS Catalogue No.: 1220.0.

14. GISCA [homepage on the Internet]. Adelaide (AUST): GISCA, University of Adelaide; 2009 [cited 2009 Mar]. About ARIA + (Accessibility/Remoteness Index of Australia). Available from: http://www.gisca.adelaide.edu.au/products_ services/ariav2_about.html

15. Zou G. A modified poisson regression approach to prospective studies with binary data. Am J Epidemiol. 2004;159(7):702-6.

16. Mackenbach JP, Kunst AE. Measuring the magnitude of socio-economic inequalities in health: an overview of available measures illustrated with two examples from Europe. Soc Sci Med. 1997;44(6):757-71.

17. Hayes LJ, Berry G. Sampling variability of the Kunst-Mackenbach relative index of inequality. J Epidemiol Community Health. 2002;56(10):762-5.

18. Weesie J. Seemingly unrelated regression and the cluster-adjusted sandwich estimator. STATA Technical Bulletin. 1999;52:34-46.

19. Young AF, Dobson AJ, Byles JE. Health services research using linked records: who consents and what is the gain? Aust $N Z J$ Public Health. 2001;25(5):417-20.

20. van Doorslaer E, Clarke P, Savage E, Hall J. Horizontal inequities in Australia's mixed public/private health care system. Health Policy. 2008;86(1):97-108.
21. van Doorslaer E, Masseria C, Koolman X, for the OHERG. Inequalities in access to medical care by income in developed countries. CMAJ. 2006;174(2):177-83.

22. Parslow R, Jorm A, Christensen H, Jacomb P. Factors associated with young adults' obtaining general practitioner services. Aust Health Rev. 2002;25(6):109-18.

23. Overland J, Hayes L, Yue DK. Social disadvantage: its impact on the use of Medicare services related to diabetes in NSW. Aust $N Z J$ Public Health. 2002;26(3):262-5.

24. Parslow RA, Jorm AF. Who uses mental health services in Australia? An analysis of data from the National Survey of Mental Health and Wellbeing. Aust N ZJ Psychiatry. 2000;34(6):997-1008.

25. Keeffe JE, Weih LM, McCarty CA, Taylor HR. Utilisation of eye care services by urban and rural Australians. Br J Ophthalmol. 2002;86(1):24-7.

26. Walker BF, Muller R, Grant WD. Low back pain in Australian adults health provider utilization and care seeking. $J$ Manipulative Physiol Ther. 2004;27(5):327-35.

27. Adams C, Slack-Smith L, Larson A, O'Grady M. Dental visits in older Western Australians: a comparison of urban, rural and remote residents. Aust J Rural Health. 2004;12(4):143-9.

28. van Doorslaer E, Massiera C. Income-related inequality in the use of medical care in 21 OECD countries. In: Towards High-performing Health Systems: Policy Studies (OECD Health Project). Paris (FRA): OECD; 2004. p. 109-65.

29. Roberts-Thomson KF, Luzzi L, Brennan DS. Social inequality in use of dental services: relief of pain and extractions. Aust $N Z J$ Public Health. 2008;32(5):444-9.

30. Xue CC, Zhang AL, Lin V, Da Costa C, Story DF. Complementary and alternative medicine use in Australia: a national population-based survey. J Altern Complement Med. 2007;13(6):643-50.

31. van Ryn M, Burke J. The effect of patient race and socio-economic status on physicians' perceptions of patients. Soc Sci Med. 2000;50(6):813-28.

32. Furler J, Stewart A, Sims J, Naccarella L. Patient social and economic circumstances - GP perceptions and their influence on management. Aust Fam Physician. 2005;34(3):189-92. 